(C) 2021, The Authors. Published by Elsevier Inc. and Fass Inc. on behalf of the American Dairy Science Association ${ }^{\circledR}$. This is an open access article under the CC BY-NC-ND license (http://creativecommons.org/licenses/by-nc-nd/4.0/).

\title{
Homogeneity density scores of quarter milk in automatic milking systems
}

\author{
C. Hallén Sandgren, ${ }^{1}$ D. Anglart, ${ }^{1 *} \oplus$ I. C. Klaas, ${ }^{1} \oplus$ L. Rönnegård, ${ }^{2,3} \oplus$ and U. Emanuelson ${ }^{4} \oplus$ \\ ${ }^{1}$ DeLaval International AB, PO Box 39, SE-147 21 Tumba, Sweden \\ ${ }^{2}$ School of Technology and Business Studies, Dalarna University, SE-791 88 Falun, Sweden \\ ${ }^{3}$ Department of Animal Breeding and Genetics, Swedish University of Agricultural Sciences, PO Box 7023, SE-750 07 Uppsala, Sweden \\ ${ }^{4}$ Department of Clinical Sciences, Swedish University of Agricultural Sciences, PO Box 7054, SE-50 07 Uppsala, Sweden
}

\begin{abstract}
Milk quality and clinical mastitis in dairy cows are monitored by detecting visually abnormal milk. A standardized method to evaluate clots in milk and studies of the incidence and dynamics of clots in milk at the quarter level are lacking. We validated a method to score clot density in quarter milk samples and describe the prevalence and dynamics of the density scores between consecutive samplings and periods in 4 farms with automatic milking systems. Using in-line filters, we collected quarter milk samples at each milking during 3 periods of $30 \mathrm{~h}$ each in each farm. Clot density was scored based on coverage of the filter area as 0 (negative), 1 (trace), 2 (mild), 3 (moderate), 4 (heavy), and 5 (very heavy). The score for a specific quarter and milking is referred to as the quarter milking score (QMS). Three assessors independently scored $902 \mathrm{im}-$ ages of filter samples with a Fleiss kappa value of 0.72 . In total, 21,202 quarter milk samples from 5,398 milkings of 621 cows were collected. Of the quarter filter samples, $2.4 \%$ had visible clots, distributed as mild $(1.4 \%)$, moderate $(0.6 \%)$, heavy $(0.3 \%)$, and very heavy $(<0.1 \%, \mathrm{n}=8)$. Cases with a cow period sum of QMS $\geq 4$, corresponding to $9.4 \%$ of all periods, harbored $86 \%$ and $94 \%$ of all QMS of 2 to 5 and 3 to 5 , respectively. Of these cases, cows sampled in all 3 periods and clots in only 1 period had a quarter period sum score $\geq 1$ in 1.8 different quarters in average. Corresponding numbers for the cows with clots or traces in 2 or 3 periods were 2.2 and 2.5 different quarters, respectively. A QMS of 2 to 5 in the preceding milking increased the chance of a QMS $>1$ in the following milking, with an average chance of $38 \%$. The probability of a QMS $>1$ increased with increasing previous QMS, a higher sum of QMS during the milking period, longer milking interval, and higher lactation number, but decreased
\end{abstract}

Received March 11, 2021.

Accepted May 5, 2021.

*Corresponding author: dorota.anglart@delaval.com with increasing days in milk. Our study showed that the method of clot-density scoring is feasible to perform and reproducible for investigating the occurrence and dynamics of clots in milk. Elevated clot-density scores clustered within certain cows and cow periods and appeared in new quarters of the cows over time. The low recurrence of QMS of 1 and 2 within quarters indicated that QMS 3 could be a reasonable threshold for detecting quarters with abnormal milk that require further attention.

Key words: mastitis, dairy cow, clot, quarter milk, score

\section{INTRODUCTION}

Detecting changes in milk homogeneity, such as the presence of clots and flakes in milk, is an important and widely accepted part of monitoring milk quality and mastitis in dairy farms. In conventional milking systems, the milking personnel typically inspect foremilk before attaching the milking unit to find and potentially treat cases of mastitis as well as to divert poor-quality milk from the bulk tank holding milk for human consumption. Inspection of foremilk is mandatory in the European Union and promoted elsewhere (European Commission, 2004; National Mastitis Council, 2013), but is not always conducted in farms (Wenz et al., 2007; Nielsen and Emanuelson, 2013). In herds with automatic milking systems (AMS), foremilk cannot be visually assessed. Instead, sensors monitor inflammation markers such as electrical conductivity, milk color, milk yield, and milking characteristics. Changes in milk homogeneity, such as the occurrence of clots $\geq 2 \mathrm{~mm}$ in size, have been suggested as part of the standard for evaluating milk quality in AMS (International Organization for Standardization, 2007a). Hence, the clot size needs to be judged or scored for evaluation purposes. Pouring milk through a filter is suggested as a universal and consistent method for detecting clot presence (Rasmussen et al., 2005).

For research purposes in conventional milking systems, similar filter-based methods as those suggested 
by Rasmussen et al. (2005) have been applied to define cases of visually abnormal milk. In these methods, clots are collected throughout the milking using commercially available in-line filters and scored visually for homogeneity according to a scale (Claycomb et al., 2009; Kamphuis et al., 2013, 2016). Studies using such methods indicate that low densities of clots may occur on single occasions, possibly without any special need for special treatment of the cow. However, studies describing the dynamics of clot density in detail and at the quarter level have hitherto been lacking.

Although the prestripping of quarters has long been practiced, little is known of the occurrence and degree of severity of the changes in milk homogeneity in commercial dairy herds. To our knowledge, epidemiological studies describing the incidence and dynamics of milk homogeneity changes at the cow and quarter levels over time, and describing the variables affecting the prevalence and repeatability of these changes, are lacking. The lack of a validated and feasible method for assessing individual udder quarters of cows at the farm level impedes the exploration of the occurrence and severity of homogeneity changes in milk. Furthermore, such methods and descriptive epidemiology are essential for setting industrial standards and developing the required technologies for detection.

The main aims of this study were to assess the prevalence, dynamics between sampling periods, and repeatability within sampling periods of milk clots in AMS. The specific objectives were (1) to develop and validate an objective method to assess and score milk clot density of quarter whole milk, (2) to describe the prevalence and dynamics of clots of different densities over time, and (3) to identify cow variables affecting the chances of certain clot density scores.

\section{MATERIALS AND METHODS}

\section{Data Collection}

Data were collected from 4 commercial dairy farms using AMS (VMS, DeLaval International AB) that were selected based on willingness to participate and the presence of additional sensors deemed necessary for a companion study. The cows were milked in a total of 10 AMS. Two of the selected farms were located in Sweden (farms A and B) and 2 in the Netherlands (farms C and D).

The data were collected between March 2017 and April 2018, and each farm was visited on 3 occasions at 2- to 4 -wk intervals. The farm visits took place over 2 mo at farms $\mathrm{A}$ and $\mathrm{B}$ and, for practical reasons, over 3 mo at farms $\mathrm{C}$ and $\mathrm{D}$. The cows involved in the data collection were mainly Holstein-Friesian; farm D was an exception, with approximately half of the herd being Fries-Hollands. On each visit, visual milk inspection (MI) of all udder quarters milked during 30 consecutive hours was performed, henceforth referred to as "periods." All cows milked in the AMS during each period participated in the MI. The number of MI per cow and period thus depended on the number of AMS visits of each cow. Supplemental Table S1 (https: //pub.epsilon.slu.se/23920/) summarizes details of the data collection, number of AMS, number of cows, parity, DIM, yearly milk production, and bulk tank SCC at each farm.

\section{Milk Inspections}

The MI to identify clots were performed using a meshed filter, the Vision 16 Mastitis Detector (Ambic Equipment Limited), providing a representative sample of clots throughout the milking of each quarter. For each AMS, a filter with holder was installed along the milk tube (International Organization for Standardization, 2007b) before the milk meter of each teat cup (Figure 1). Each quarter was separately sampled as follows. For each AMS, after a cow milking, the filters were removed from the holder and visually inspected for clots one by one. Each filter was first gently rinsed with water from above to remove milk and foam, after which it was visually inspected (Rasmussen, 2005). If there were no signs of clots, no photo was taken, and the filter was cleaned and returned to the holder along the milking tube. If clots or suspected traces of clots were visible on the filter, the filter or filters (if more than 1 per cow) were put in a box with 4 positions (Supplemental Figure S1, https://pub.epsilon.slu.se/23920/) and photographed together with the AMS number, cow number, quarter location, time, and date. A second picture, a close-up of each filter, was then taken to be used for visual scoring. Each MI image was stored together with notes on any deviations, such as mixed-up cups during milking and uncertainty regarding the cow number or quarter locations. The sample was marked as failed if the MI was not performed for some reason. The MI were performed by 3 persons, whereof 1 was the second author, who was also responsible for training of the 2 support persons, 1 in Sweden and 1 in the Netherlands.

\section{Scale for Clot Scoring}

The scoring scale provided by the supplier of the meshed filter assumed sampling at the cow composite level. Because the MI was performed at the quarter level, the density of clots sampled by the filter was as- 


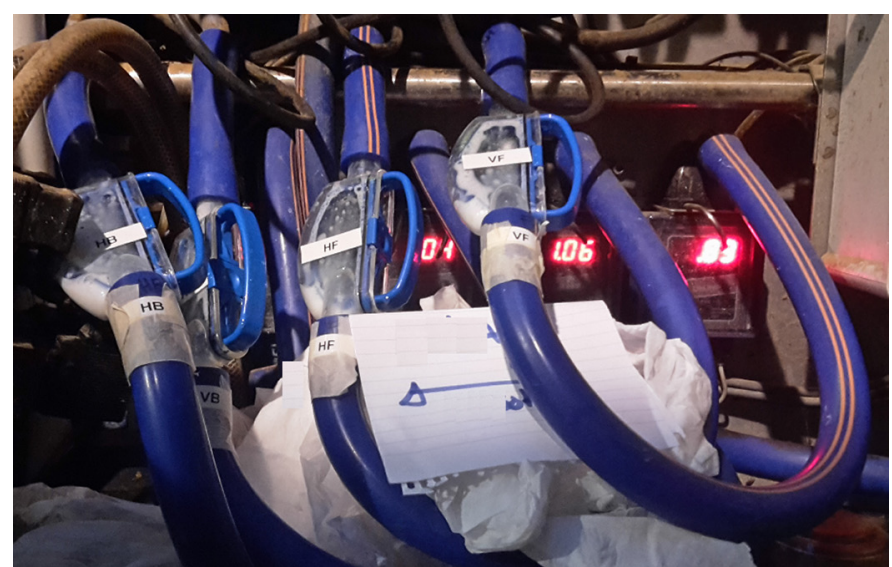

Figure 1. Installation of holders and filters along the milk tube before the milk meter of each teat cup.

sumed to vary more than at the cow composite level. A scale, adjusted to scoring clots at the quarter level, was therefore defined using 200 images collected at farm A before the trial for training and evaluation purposes.

The scale ranged between 0 and 5 , with a score of 0 being defined as no signs of clots on the filter. A score of 1 was defined as a trace, with the total size of the assembled deposits on the filter being $<3 \mathrm{~mm}$ in diameter. A score of 2 was defined as a mild assembly of clots, with the total size of the deposits being $\geq 3$ $\mathrm{mm}$ in diameter. A score of 3 was defined as a moderate assembly of clots, with the total size of the deposits being $\geq 5 \mathrm{~mm}$ in diameter or covering approximately $10 \%$ of the filter. A score of 4 was defined as a heavy assembly of clots, corresponding to 10 to $50 \%$ of the filter area covered with clots. A score of 5 was defined as a very heavy assembly of clots, corresponding to $>50 \%$ of the filter area covered with clots. Table 1 provides an overview of the scores and definitions, and Figure 2 depicts scores of 0 to 5 .

\section{Scoring of Clots}

The images showing signs of clots were scored when the data collection was completed at all farms. Three

Table 1. Definitions of milk homogeneity density scores 0 to 5

\begin{tabular}{lll}
\hline Score & Definition & Area of the filter covered with clots \\
\hline 0 & No signs & None \\
1 & Trace & Diameter $<3 \mathrm{~mm}$ \\
2 & Mild case & Diameter $\geq 3 \mathrm{~mm}$ to $<21 \mathrm{~mm}$ \\
3 & Moderate case & Diameter $\geq 21 \mathrm{~mm}$ to $<10 \%$ of the \\
& filter area \\
4 & Heavy case & $\geq 10 \%$ to $<50 \%$ of the filter area \\
5 & Very heavy case & $\geq 50 \%$ of the filter area \\
\hline
\end{tabular}

assessors (2 veterinarians and an animal scientist) not involved in the data collection were trained at a joint session by assessing the images collected in the pilot study. Subsequently, the assessors scored each image individually using the 1 to 5 scoring scale so that each image received 3 scores. If at least 2 out of 3 assessors' scores agreed, the MI was set as the quarter milking score (QMS); if there was complete disagreement, the score was removed from the data set, which was the case for 3 MI. During the scoring, the assessors had access to reference images for each score retrieved from the 200 images from the training. Scorer agreement was assessed on all successfully scored images from the trial using Fleiss kappa (Fleiss, 1971), with 3 raters computed using the "irr" package in R (Gamer et al., 2019).

\section{Definitions of Combined Scores}

Only cow periods with at least 2 milkings and completed MI during the period were included in the analyses. Two definitions of summary scores were used for the analyses: the quarter period sum score (QPSS; i.e., the sum of all QMS per quarter, period, and cow) and the cow period sum score (CPSS; i.e., the sum of all QMS per period and cow; Figure 3).

\section{Data Analysis}

Descriptive statistics were used to illustrate the score dynamics. To better understand the QMS dynamics between periods, we further selected all cows with 3 periods and at least 1 CPSS $\geq 4$. For this subset, we calculated the following: number of periods with CPSS $\geq 1$, average number of QPSS $\geq 1$ per cow, average number of quarters with QPSS $\geq 1$ per cow, and percentage of all QPSS $\geq 1$ appearing in the same quarter.

To assess how indicative the CPSS was of the likelihood of any chosen QMS being positive in a period, data were analyzed using a logistic regression model with PROC GENMOD of SAS 9.4 (SAS Institute Inc.). The outcome variable was QMS status, being either positive (QMS $\geq 2$ ) or negative (QMS $<2$ ) of each MI. The main explanatory variable was the CPSS of the MI, but with the QMS of the actual MI subtracted (aCPSS), to avoid a circular reference in the model (i.e., the QMS of the MI on both sides of the equation). The other explanatory variables were cow (repeated factor), farm, breed, parity, period, quarter location, status of the quarter at the previous milking (i.e., positive, negative, or unknown), DIM, quarter milk yield $(\mathrm{kg})$, and milking interval ( $\mathrm{min})$.

The functional forms of the continuous variables (i.e., aCPSS, DIM, quarter milk yield, and milking inter- 
Score $=0$

Score $=1$

Score $=\mathbf{2}$
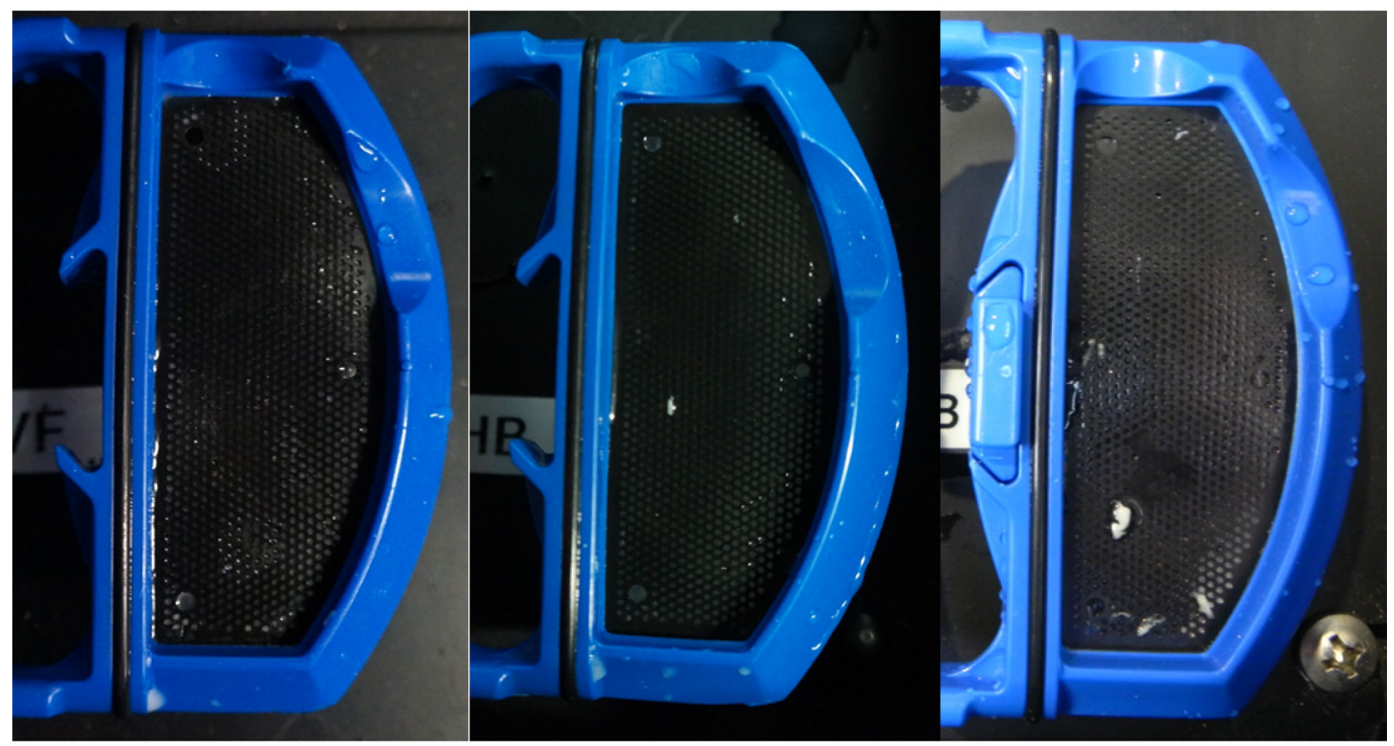

Score $=\mathbf{3}$

Score $=4$

Score $=\mathbf{5}$

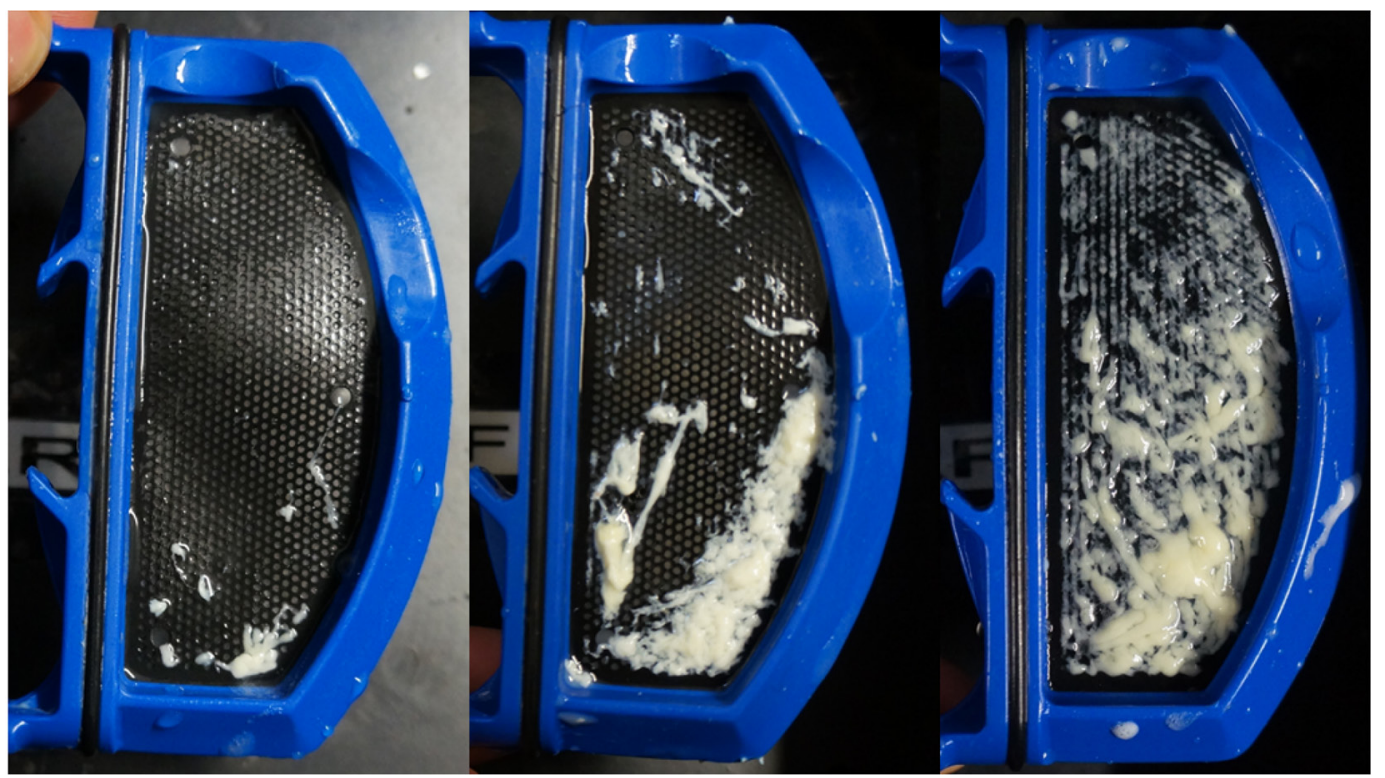

Figure 2. Score, definition, and aggregate area of deposits on the filters scored for density.

val) were first evaluated using a generalized additive model, fitted as splines. Subsequently, the functional forms, indicated by the generalized additive model results, were coded with appropriate polynomials, but nonsignificant higher-order terms were removed from the model to have as parsimonious a model as possible. The quadratic (and cubic) terms of the continuous variables were calculated after centering on the mean within cow to reduce the collinearity between linear and higher-order terms. Model results are presented as parameter estimates, but also as marginal means for different levels of aCPSS, converted using the inverse of the logit-link function (i.e., as predicted probabilities).

\section{RESULTS}

\section{Scoring Method}

From the collected 932 images of 303 unique cows, 30 quarter milkings were discarded due to failed sam- 
pling, unknown cow number, or missing image. Of the remaining 902 images available for QMS assessment, 7 images received a score of 0,379 images received a score of 1, 303 images received a score of 2, 135 images received a score of 3, 67 images received a score of 4 , and 8 images received a score of 5 . Three of the images were discarded due to scorer disagreement. The kappa value comparing agreement between scorers was 0.72 , indicating substantial agreement (Landis and Koch, 1977), and all 3 scorers were in complete agreement for 638 of the 899 retained images. Twenty-two cows were milked and inspected only once during a period and were removed from the data set, resulting in 880 quarter milkings with approved scores $>0$ available for analysis. Due to the extremely low density in the samples scored as trace (i.e., score of 1), these were judged as not having visible clots.

\section{Descriptive Statistics}

In total, there were 1,630 periods with 5,389 cow milkings from 621 cows and 21,202 quarters inspected in the data analyzed. The average numbers of MI per cow within a period were 3.0, 3.2, 3.8, and 3.4 for herds $\mathrm{A}, \mathrm{B}, \mathrm{C}$, and $\mathrm{D}$, respectively. The overall proportion of visible clots (QMS 2-5) was $2.4 \%$, and the moderate to heavy density cases (QMS 3-5) constituted $1.0 \%$ of all MI (Supplemental Table S2, https://pub.epsilon.slu.se/ $23920 /$ ). The proportion of visible clots varied between farms from $1.6 \%$ to $3.4 \%$, and of moderate to heavy cases from $0.8 \%$ to $1.6 \%$.

\section{CPSS and QMS Distribution}

The CPSS ranged from 0 to 50 (Table 2). In total, 294 cow periods $(18.0 \%)$ contained all visible clots (QMS > $1)$. There were $153(9.4 \%)$ periods with CPSS $\geq 4$, accounting for $68.5 \%, 88.1 \%$, and $100 \%$ of the QMS for mild, moderate, and heavy cases, respectively (Table 2 ). Furthermore, all cow periods for cows with at least 1 CPSS $\geq 4$ accounted for $311(19.1 \%)$ of all periods, represented by $116(18.7 \%)$ of all cows and including $79.7 \%, 91.0 \%$, and $100 \%$ of the QMS for mild, moderate, and heavy cases, respectively. Among these 116 cows, a QMS of 1 was found in 201 MI, which was 4.9 times higher per milked quarter than in the MI of the remaining cows; the corresponding numbers for QMS of 2 and 3 were 16.2 and 41.9 times higher, respectively.

\section{Score Dynamics Between Periods}

The 88 cows in the subset of cows with 3 sampling periods and at least 1 CPSS $\geq 4$ were analyzed further, including all scores and also including traces, as they were found to be overrepresented. Seven of these cows had CPSS $\geq 4$ in all 3 periods, 20 cows had CPSS $\geq$ 4 in 2 periods, and 61 had CPSS $\geq 4$ in only 1 period. These cows had 264 cow periods, of which 181 (69\%) had CPSS $\geq 1$, with most having 2 or 3 periods (31 periods each) with CPSS $\geq 1$ (Table 3 ). In all periods, the number of quarters with QPSS $\geq 1$ was a maximum of 3, and the average number of quarters with QPSS $\geq$ 1 in any period was 1.7 , independent of the number of

\begin{tabular}{|c|c|c|c|c|c|c|c|c|c|c|c|c|c|c|c|c|c|c|}
\hline \multicolumn{7}{|c|}{ Period 1} & \multicolumn{6}{|c|}{ Period 2} & \multicolumn{6}{|c|}{ Period 3} \\
\hline Cow & Quarter & MI 1 & MI 2 & MI 3 & QPSS & CPSS & MI 1 & MI 2 & MI 3 & MI 4 & QPSS & CPSS & MI 1 & MI 2 & MI 3 & MI 4 & QPSS & CPSS \\
\hline \multirow[t]{4}{*}{1} & Left rear & 2 & 0 & 2 & 4 & \multirow[t]{4}{*}{8} & 2 & 1 & & & 2 & \multirow[t]{4}{*}{2} & 3 & 2 & & & 5 & \multirow[t]{4}{*}{9} \\
\hline & Left front & 1 & 0 & 0 & 0 & & 0 & 0 & & & 0 & & 2 & 0 & & & 2 & \\
\hline & Right front & 2 & 0 & 2 & 4 & & 0 & 0 & & & 0 & & 0 & 2 & & & 2 & \\
\hline & Right rear & 0 & 0 & 0 & 0 & & 0 & 1 & & & 0 & & 0 & 0 & & & 0 & \\
\hline \multirow[t]{4}{*}{ II } & Left rear & 2 & 3 & & 5 & \multirow[t]{4}{*}{18} & 0 & 0 & 0 & 0 & 0 & \multirow[t]{4}{*}{2} & 0 & 0 & 0 & 0 & 0 & \multirow[t]{4}{*}{0} \\
\hline & Left front & 3 & 3 & & 6 & & 0 & 0 & 0 & 0 & 0 & & 0 & 0 & 0 & 1 & 0 & \\
\hline & Right front & 0 & 0 & & 0 & & 0 & 0 & 0 & 0 & 0 & & 0 & 0 & 0 & 0 & 0 & \\
\hline & Right rear & 3 & 4 & & 7 & & 1 & 0 & 0 & 2 & 2 & & 0 & 0 & 0 & 0 & 0 & \\
\hline \multirow[t]{4}{*}{ III } & Left rear & 0 & 0 & & 0 & \multirow[t]{4}{*}{0} & 0 & 0 & & & 0 & \multirow[t]{4}{*}{0} & 0 & 0 & & & 0 & \multirow[t]{4}{*}{5} \\
\hline & Left front & 0 & 0 & & 0 & & 0 & 0 & & & 0 & & 0 & 0 & & & 0 & \\
\hline & Right front & 0 & 0 & & 0 & & 0 & 0 & & & 0 & & 0 & 2 & & & 2 & \\
\hline & Right rear & 0 & 0 & & 0 & & 0 & 0 & & & 0 & & 3 & 0 & & & 3 & \\
\hline \multirow[t]{4}{*}{ IV } & Left rear & 0 & 0 & 0 & 0 & \multirow[t]{4}{*}{5} & 0 & 0 & 0 & & 0 & \multirow[t]{4}{*}{10} & 0 & 0 & & & 0 & \multirow[t]{4}{*}{6} \\
\hline & Left front & 0 & 1 & 2 & 2 & & 2 & 1 & 2 & & 4 & & 3 & 3 & & & 6 & \\
\hline & Right front & 0 & 0 & 1 & 0 & & 0 & 0 & 0 & & 0 & & 0 & 0 & & & 0 & \\
\hline & Right rear & 3 & 1 & 0 & 3 & & 3 & 3 & 0 & & 6 & & 0 & 0 & & & 0 & \\
\hline
\end{tabular}

Figure 3. Examples of scores within milk inspections (MI), quarter period sum score (QPSS), and cow period sum score (CPSS) distributions for 4 cows with CPSS $\geq 4$ in 1 or more periods. 
Table 2. Distribution of quarter milk scores (QMS) per cow period sum score (CPSS)

\begin{tabular}{|c|c|c|c|c|c|c|c|}
\hline CPSS (n) & \multicolumn{7}{|c|}{ QMS, n (row \%) } \\
\hline $0(1,203)$ & $15,582(100)$ & $0(0)$ & $0(0)$ & $0(0)$ & $0(0)$ & $0(0)$ & 15,582 \\
\hline $2(96)$ & $1,157(90.5)$ & $52(4.1)$ & $70(5.5)$ & $0(0)$ & $0(0)$ & $0(0)$ & 1,279 \\
\hline $3(45)$ & $524(87)$ & $37(6.1)$ & $25(4.2)$ & $16(2.7)$ & $0(0)$ & $0(0)$ & 602 \\
\hline $4(39)$ & $430(82.7)$ & $38(7.3)$ & $40(7.7)$ & $10(1.9)$ & $2(0.4)$ & $0(0)$ & 520 \\
\hline $7(11)$ & $104(73.8)$ & $12(8.5)$ & $14(9.9)$ & $7(5.0)$ & $4(2.8)$ & $0(0)$ & 141 \\
\hline $8(15)$ & $113(69.8)$ & $12(7.4)$ & $14(8.6)$ & $13(8.0)$ & $9(5.6)$ & $1(0.6)$ & 162 \\
\hline $9(11)$ & $102(68.9)$ & $11(7.4)$ & $23(15.5)$ & $7(4.7)$ & $4(2.7)$ & $1(0.7)$ & 148 \\
\hline $10(9)$ & $70(66.7)$ & $5(4.8)$ & $13(12.4)$ & $9(8.6)$ & $8(7.6)$ & $0(0)$ & 105 \\
\hline $11-15(14)$ & $137(67.2)$ & $12(5.9)$ & $23(11.3)$ & $17(8.3)$ & $14(6.9)$ & $1(0.5)$ & 204 \\
\hline $16-20(5)$ & $42(58.3)$ & $1(1.4)$ & $9(12.5)$ & $12(16.7)$ & $4(5.6)$ & $4(5.6)$ & 72 \\
\hline $21-50(6)$ & $35(35)$ & $7(7)$ & $17(17)$ & $20(20)$ & $20(20)$ & $1(1)$ & 100 \\
\hline
\end{tabular}

periods with CPSS $\geq 1$ (data not shown). The number of individual quarters with QPSS $\geq 1$ at least once increased with the number of periods with CPSS $\geq 1$ and varied from 1 to 4 quarters (Table 3; Supplemental Figure S2, https://pub.epsilon.slu.se/23920/).

\section{Score Dynamics Within Period}

Of 338 quarters with scores of 2 to $5,37.9 \%$ had QMS $\geq 2$ at the following milking. More specifically, $21.7 \%$ and $53.3 \%$ of the quarters with QMS of 2 and 3 , respectively, had QMS $\geq 2$ at the following MI. Corresponding figure for quarters with QMS of 4 and 5 was $74.0 \%$. Of the negative samples (i.e., QMS $=0$ or 1), $98.4 \%$ remained negative at the following MI. Of the 21,202 QMS, 6,405 did not have a milking before the MI in the data set. In these samples, the QMS was negative in $97.8 \%$ of the cases (i.e., similar to the overall proportion of negative QMS; Table 4). The results of the logistic regression analysis showed that the linear and quadratic terms for aCPSS, previous QMS, DIM, milking interval, lactation number, and farm were significantly associated with the probability of observing a positive QMS (Table 5). The probability of a cow having a positive QMS decreased with increasing number of DIM; for example, the odds of a positive QMS were 0.55 times lower for cows at 300 rather than at 30 DIM. A longer milking interval corresponded to increased odds of a cow having a positive QMS; for example, the odds of a positive QMS were 1.8 times higher for a milking interval of 12 rather than $6 \mathrm{~h}$. In general, the probability of any random QMS being positive were very low $(2.4 \%)$, as shown earlier in Table 4. The odds of a random quarter in a period having visible clots (QMS $\geq 2$ ) increased with higher aCPSS, but in a nonlinear fashion, as illustrated in Figure 4. Up to aCPSS of 9 to 10, we observed a slow increase, with a steeper increase at higher aCPSS values. The probability increased to $10 \%$ at an aCPSS of 7 and to $30 \%$ at an aCPSS of 14 . Cows with aCPSS $>18$ had a greater than $50 \%$ probability of clots.

\section{DISCUSSION}

Detecting homogeneity changes in milk for the surveillance of milk quality is widely recommended, and legislated in the European Union, for all milking systems (Commission Directive 89/362/EEC; National Mastitis

Table 3. Distribution of quarter period sum scores (QPSS) $\geq 1$ for cows with varying numbers of cow period sum scores (CPSS) $\geq 1$ and average number of quarter periods with QPSS $\geq 1$, among cows with 3 periods and at least 1 CPSS $\geq 4$

\begin{tabular}{lccrrr}
\hline & & \multicolumn{2}{c}{$\begin{array}{c}\text { Number of QPSS } \geq 1 \text { appearing } \\
\text { in the same quarter in 1-3 periods }\end{array}$} \\
\cline { 3 - 5 } Number of CPSS $\geq 1$ per cow & Number of cows & 1 & 2 & 3 & Average number of QPSS $\geq 1$ \\
\hline 1 & 26 & 46 & 0 & 0 & 1.8 \\
2 & 31 & 36 & 31 & 0 & 2.2 \\
3 & 31 & 28 & 32 & 19 & 2.5 \\
Total & 88 & 110 & 63 & 19 & \\
\hline
\end{tabular}


Table 4. Relationship between quarter milk scores (QMS) from 2 consecutive milk inspections

\begin{tabular}{lccccc}
\hline & \multicolumn{4}{c}{ Current QMS, \% } & \\
\cline { 2 - 5 } Previous QMS & Negative & 2 & 3 & $\geq 4$ & Number of scores \\
\hline$\leq 1$ & 98.4 & 1.2 & 0.3 & 0.1 & 14,456 \\
2 & 78.3 & 13.6 & 6.1 & 2.0 & 198 \\
3 & 46.7 & 21.1 & 22.2 & 10.0 & 90 \\
$\geq 4$ & 26.0 & 4.0 & 24.0 & 46.0 & 50 \\
Unknown & 97.6 & 1.3 & 0.7 & 0.4 & 6,405 \\
Number of scores & 6,253 & 82 & 47 & 23 & \\
\hline
\end{tabular}

Council, 2013). The challenge of such surveillance lies in agreeing on the definition of abnormal milk, a challenge that has long been known (Dodd et al., 1969), but came into focus at the time of AMS introduction (Rasmussen, 2005). Hence, homogeneity scores have been solely used as a part of the "gold standard" definition in mastitis detection studies, where clot-density scoring has been performed either by 1 scorer only (Kamphuis et al., 2013, 2016) or with no interscorer agreement reported (Kamphuis et al., 2008). To our knowledge, this is the first study developing and validating a method to identify and quantify clot density in quarter milk. The interscorer agreement in this study was substantial (Boyer and Verma 2000), which implies reliable infor-

Table 5. Parameter estimates from the logistic regression model evaluating the association between cow period sum score (aCPSS), quadratic term of cow period sum score (aCPSS_Q), and quarter milk score (QMS) status (positive: QMS $>1$, or negative: QMS $<2$ )

\begin{tabular}{llrc}
\hline Variable & Level & Estimate & $P$-value \\
\hline Intercept & & -5.1079 & \\
aCPSS & & 0.2072 & $<0.001$ \\
aCPSS_Q & & -0.0056 & $<0.01$ \\
DIM & & -0.0023 & $<0.001$ \\
Quarter yield (kg) & -0.0470 & 0.25 \\
Milking interval (min) & & 0.0017 & $<0.001$ \\
Previous QMS & Positive & 2.1960 & $<0.001$ \\
& Unknown & 0.2101 & \\
Lactation & Negative & -2 & \\
& 1 & 0.0557 & 0.03 \\
Breed & 2 & 0.3351 & \\
& $\geq 3$ & - & \\
Farm & Other & 0.0608 & 0.73 \\
& Holstein-Friesian & - & \\
& A & 0.4264 & $<0.01$ \\
B & -0.1408 & \\
Period & C & 0.2255 & \\
& D & - & \\
Quarter & 1 & -0.0149 & 0.96 \\
& 2 & -0.0334 & \\
& 3 & - & \\
& Left rear & -0.0183 & 0.82 \\
& Left front & -0.0564 & \\
\hline Right front & -0.1268 & \\
\hline
\end{tabular}

${ }^{1} P$-value for main effect.

${ }^{2}$ Reference level. mation about milk homogeneity changes for individual cows. Furthermore, data collected on several occasions from all quarters have never previously been reported, allowing us to study the prevalence of and changes in milk homogeneity of different densities over time.

The higher scores belonged mainly to a subpopulation of cows with at least $1 \mathrm{CPSS} \geq 4$. However, the scores varied considerably within quarter and between periods in the same cow. Most of these cows (i.e., 61 of 88 with 3 periods) had CPSS $\geq 4$ in only 1 period. However, these cows commonly also had CPSS between 1 and 3 in at least one of the remaining periods (Table 3 ). The number of mastitis treatments among these cows was 10 during the trial (including $10 \mathrm{~d}$ before first period), whereof 4 maintained clots in milk. Hence, this was considered to be negligible for the outcome.

Also, the number of individual quarters with QMS $\geq$ 1 was higher in cows having 2 additional periods with CPSS $\geq 1$ than in cows with only 1 or no additional period. This indicated that this subpopulation of cows had a longer period of milk homogeneity changes, but of varying degrees. Rasmussen (2005) found a strong relationship between California Mastitis Test scores and the presence of clots in milk, which suggests udder inflammation in a large proportion of cows with clots in foremilk. In our study, the pattern of clots within the affected subpopulation could reflect the typical inflammation pattern of cows with clinical signs of mastitis. Elevated CPSS scores across periods could thus indicate cows with chronic mastitis in dynamic stages of inflammation. Hence, monitoring a gradual increase as well as the dynamics of QMS over time could be a valuable tool to allow the farmer to identify cows with chronic mastitis. The dynamics of elevated QMS between the quarters of a cow warrant further investigation. It appears that a cow once affected by milk homogeneity changes, such as clots in 1 quarter, is more likely to display changes in other quarters. These dynamics have been found in other studies in which gradually increasing cow composite SCC were related to an increasing number of quarters expressing inflammation (Brolund, 1985). 
Of all samples with nonzero scores, $42 \%$ were classified as having a QMS of 1 , a score that a farmer would likely not detect or take notice of when evaluating milk samples without filtering. However, a score of 1 (i.e., trace) could be an indication of flakes in the milk. The presence of small flakes was earlier reported to be a rather poor indication of bacteriological infection or inflammation (Giesecke and van den Heever, 1974). Nevertheless, a QMS of 1 was 4.9 times more common in all MI from cows with 1 or more CPSS $\geq$ 4 than in cows with lower CPSS values. Thus, a QMS of 1 might indicate an early stage of clinical mastitis or a cow in the recovery stage of a clinical mastitis. In chronic cows, QMS of 1 could indicate a transition between a nonclinical and a clinical stage. The total number of QMS values of 1 was almost as high in cows with lower CPSS values but then was usually observed only once. Hence, a score of 1 might also have other explanations, such as a prolonged milking interval (Lakic et al., 2009). Our findings suggest that a score of 1 (i.e., trace) should be further explored to evaluate its importance in the assessment of abnormal milk and in the development of scores over time.

The results of the logistic regression model, indicating which variables were most likely associated with a positive score (i.e., QMS $\geq 2$ ), were expected, with the exception of milking interval. The pathophysiological background of clots in mastitis cow milk is not fully understood. A prolonged milking interval (up to $24 \mathrm{~h}$ ) has not been identified as a risk factor for clinical mastitis, but seems to increase the number of PMN cells in milk from previously healthy udders (Lakic et al., 2009). The proteolytic activity of proteases released from somatic cells (e.g., PMN cells) during inflammation induces the generation of para- $\kappa$-casein and leads to the precipitation of caseins in mastitis milk, which has been described as one of the mechanisms behind clot formulation (Rasmussen and Larsen, 2003). Therefore, it is possible that, depending on various factors such as the possible presence and type of bacteria and stage of inflammation in the udder, a prolonged milking interval might increase the risk of clots in milk even though the risk of clinical mastitis does not increase. The milking interval can thus give additional information regarding the occurrence of clots.

The application of a clot-density scale with scores between 0 and 5 , based on filter coverage, can be regarded as a semiquantitative method that estimates the approximate concentration of clots in milk (Bertin, 1978). In contrast to Rasmussen (2005), we found substantial agreement between scorers. It should be considered that Rasmussen (2005) used clots in the foremilk of cows, and we used the whole milk yield of a quarter during a milking. Rasmussen (2005) also used a dichotomized scale (i.e., the presence or absence of clots) and found reasonable agreement in sensitivity and specificity when the samples were analyzed in a laboratory setting by pouring collected milk through a filter. This indicates acceptable interscorer agreement in a laboratory environment. Our results support the

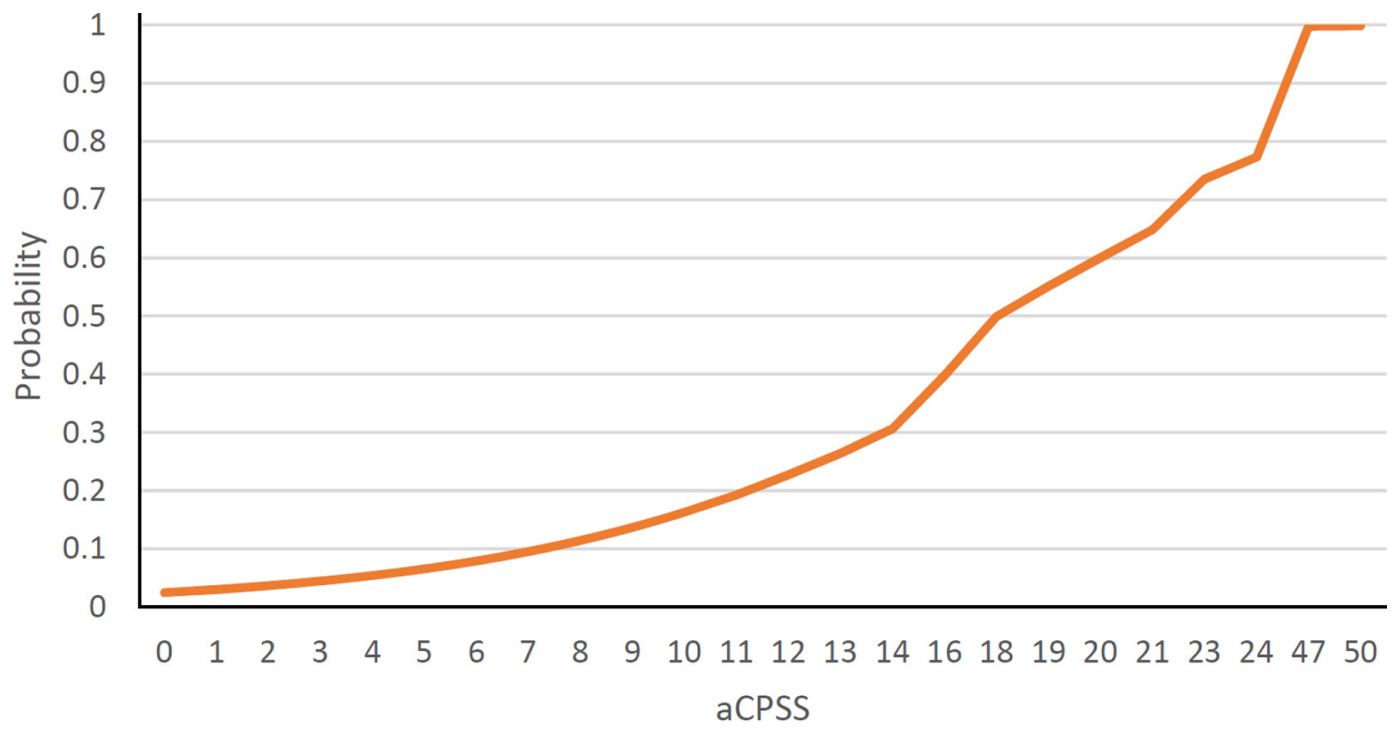

Figure 4. Predicted probabilities of a positive quarter milk score (QMS; QMS >1), calculated as marginal means at different levels of cow period sum score (aCPSS, cow period sum score of the milk inspection, but with the QMS of the specific milk inspection subtracted), as estimated in a logistic regression model and converted using the inverse logit-link function. 
view that assessing the total area of clots, unlike the earlier used clot size (Rasmussen et al., 2005), is likely to be more closely related to the total amount of clots in the milk (Rasmussen, 2005). The validity of the scoring system was supported by the significantly higher chance of an elevated score if the preceding MI had a positive score, particularly if the score was high.

By collecting composite udder milk samples, clots from several different quarters are gathered for assessment on the filters, which naturally will affect the density. Compared with other studies assessing in-line filter density (Kamphuis et al., 2013, 2016), we collected samples at the quarter level, which probably allowed the use of a more versatile scale of homogeneity scores (i.e., $1-5$ vs. the previously used 1-3). Furthermore, the density score of each individual quarter cannot be captured using composite samples, which was demonstrated here and also indicated by the larger proportion of higher scores from cow composite milk (Claycomb et al., 2009; Kamphuis et al., 2013, 2016), because udders with higher scores often have more than 1 quarter with clots or flakes and may also include lower scores hidden in the whole milk.

To our knowledge, no studies have applied a reproducible clot-density scale to milk samples. However, it has been proposed that true mastitis cases should be limited to including only those with high clot density or, alternatively, with the repetitive occurrence of clots in consecutive milkings (Rasmussen et al., 2005; Claycomb et al., 2009; Kamphuis et al., 2016). From our study, we can conclude that low density scores have lower repeatability. Based on our results, we would not recommend setting the requirement to detect density scores with a repeatability below $50 \%$. In this study, this translates into scores of 1 and 2 not being targeted as true mastitis cases.

\section{CONCLUSIONS}

We further developed and validated a semiquantitative method to score clot density at the quarter level that achieved substantial interobserver agreement and can be applied in further studies. The distribution and dynamics of the QMS and CPSS values over time showed that elevated clot-density scores were found in a limited subgroup of the cows. However, the trial was conducted in a small number of herds over a limited period, so more research into differences between herds and types of mastitis is called for. In such studies, it would be preferable to also follow bacteriological findings and inflammatory markers such as SCC in the same quarters.

\section{ACKNOWLEDGMENTS}

Financial support for this study was provided by the Swedish Foundation for Strategic Research (SSF, Stockholm, Sweden). We thank the Kjell and Märta Beijer Foundation (Stockholm) for funding Lars Rönnegård. We additionally thank the farmers participating in this study and a special thanks to Johan Östlund (DeLaval International AB, Stockholm) and Harry Tuinier (Woudsend, the Netherlands) for help with the data collection. Three of the authors (C. Hallén Sandgren, D. Anglart, and I. C. Klaas) are employed by DeLaval International AB. The authors have not stated any other conflicts of interest.

\section{REFERENCES}

Bertin, E. P. 1978. Qualitative and Semiquantitative Analysis. Pages 255-278 in Introduction to X-Ray Spectrometric Analysis. Springer. https://doi.org/10.1007/978-1-4899-2204-5_7.

Boyer, K., and R. Verma. 2000. Multiple raters in survey-based operations management research: A review and tutorial. Prod. Oper. Manag. 9:128-140. https://doi.org/10.1111/j.1937-5956.2000 .tb00329.x.

Brolund, L. 1985. Cell counts in bovine milk. Causes of variation and applicability for diagnosis of subclinical mastitis. Acta Vet. Scand. Suppl. 80:1-123.

Claycomb, R. W., P. T. Johnstone, G. A. Mein, and R. A. Sherlock. 2009. An automated in-line clinical mastitis detection system using measurement of conductivity from foremilk of individual udder quarters. N. Z. Vet. J. 57:208-214. https://doi.org/10.1080/ 00480169.2009.36903.

Dodd, F. H., D. R. Westgarth, F. K. Neave, and R. G. Kingwill. 1969. Mastitis - The strategy of control. J. Dairy Sci. 52:689-695. https: //doi.org/10.3168/jds.S0022-0302(69)86631-2.

European Commission. 2004. Commission Directive 89/362/EEC.

Fleiss, J. 1971. Measuring nominal scale agreement among many raters. Psychol. Bull. 76:378-382. https://doi.org/10.1037/h0031619.

Gamer, M., J. Lemin, and I. Fellows Puspendra Sing. 2019. Irr: Various coefficients of interrater reliability and agreement. Accessed Oct. 10, 2020. https://cran.r-project.org/web/packages/irr/irr.pdf.

Giesecke, W. H., and L. W. van den Heaver. 1974. The diagnoses of bovine mastitis with particular reference to subclinical mastitis: A critical review of relevant literature. Onderstepoort J. Vet. Res. 41:169-211.

International Organization for Standardization (ISO). 2007a. Automatic milking installations-Requirements and testing (Installations de traite automatique-Exigences et essais). 1st ed. ISO.

International Organization for Standardization (ISO). 2007b. Milking machine installations-Vocabulary (Installations de traite mécanique - Vocabulaire). 3rd ed. ISO.

Kamphuis, C., B. Dela Rue, G. Mein, and J. Jago. 2013. Development of protocols to evaluate in-line mastitis-detection systems. J. Dairy Sci. 96:4047-58. https://doi.org/10.3168/jds.2012-6190.

Kamphuis, C., B. T. Dela Rue, and C. R. Eastwood. 2016. Field validation of protocols developed to evaluate in-line mastitis detection systems. J. Dairy Sci. 99:1619-1631. https://doi.org/10.3168/jds .2015-10253.

Kamphuis, C., D. Pietersma, R. van der Tol, M. Wiedemann, and H. Hogeveen. 2008. Using sensor data patterns from an automatic milking system to develop predictive variables for classifying clinical mastitis and abnormal milk. Comput. Electron. Agric. 62:169181. https://doi.org/10.1016/j.compag.2007.12.009.

Lakic, B., E. Wredle, K. Svennersten-Sjaunja, and K. Östensson. 2009. Is there a special mechanism behind the changes in somatic cell 
and polymorphonuclear leukocyte counts, and composition of milk after a single prolonged milking interval in cows? Acta Vet. Scand. 51:4. https://doi.org/10.1186/1751-0147-51-4.

Landis, J. R., and G. Koch. 1977. The measurement of observer agreement for categorical data. Biometrics 33:159-174. https://doi.org/ $10.2307 / 2529310$.

National Mastitis Council. 2013. Recommended Milking Procedures, National Mastitis Council. Accessed Dec. 13, 2020. http://www .nmconline.org/wp-content/uploads/2016/09/Recommended -Milking-Procedures.pdf.

Nielsen, C., and U. Emanuelson. 2013. Mastitis control in Swedish dairy herds. J. Dairy Sci. 96:6883-6893. https://doi.org/10.3168/ jds.2012-6026.

Rasmussen, M. D. 2005. Visual scoring of clots in foremilk. J. Dairy Res. 72:406-414. https://doi.org/10.1017/S0022029905000993.

Rasmussen, M. D., and L. B. Larsen. 2003. Milking hygiene: New issues and opportunities from automatic milking. Ital. J. Anim. Sci. 2:283-289. https://doi.org/10.4081/ijas.2003.283.
Rasmussen, M. D., M. Bjerring, and F. Skjøth. 2005. Visual appearance and CMT score of foremilk of individual quarters in relation to cell count of cows milked automatically. J. Dairy Res. 72:49-56. https://doi.org/10.1017/S0022029904000627.

Wenz, J. R., S. M. Jensen, J. E. Lombard, B. A. Wagner, and R. P. Dinsmore. 2007. Herd management practices and their association with bulk tank somatic cell count on United States dairy operations. J. Dairy Sci. 90:3652-3659. https://doi.org/10.3168/ jds.2006-592.

\section{ORCIDS}

D. Anglart $\odot$ https://orcid.org/0000-0003-1412-0057

I. C. Klaas ๑ https://orcid.org/0000-0002-1397-8505

L. Rönnegård ๑ https://orcid.org/0000-0002-1057-5401

U. Emanuelson ๑ https://orcid.org/0000-0001-7889-417X 